\title{
Towards concerted government efforts? Assessing nutrition policy integration in Uganda
}

\author{
Brenda Shenute Namugumya ${ }^{1}$ - Jeroen J.L. Candel ${ }^{1}$ - Elise F. Talsma ${ }^{2} \cdot$ Catrien J.A.M. Termeer $^{1}$
}

Received: 31 October 2018 / Accepted: 9 January 2020 / Published online: 22 January 2020

(C) The Author(s) 2020

\begin{abstract}
To tackle malnutrition more effectively, Sub-Saharan African governments have developed overarching, integrative policy strategies over the past decade. Despite their popularity, little is known about their follow-up and ultimately their success (or failure). Consequently, tracking the progress of such political commitment has gained global importance. Various studies provide insights into changes in nutrition-related policies. Nevertheless, it is generally acknowledged that we have limited understanding of how nutrition concerns are explicitly addressed in policies of different ministries. This study uses a novel policy integration perspective to investigate the extent to which eight ministries in Uganda integrated nutrition concerns across their policy outputs between 2001 and 2017. The approach used assumes nutrition policy integration is a dynamic process occurring in different policy dimensions. We performed a qualitative content analysis to assess 103 policy outputs for changes in subsystems involved, policy goals, and instruments used. Overall, we found a shift towards increased integrated government action on nutrition over time. The 2011-2015 analysis period was a critical juncture where increased integration of nutrition was observed in all policy integration dimensions across all ministries. However, considerable variations in actor networks, goals, and instruments exist across sectors and over time. The sustainability of nutrition integration efforts remains contentious, because of which continuous monitoring will be essential.
\end{abstract}

Keywords Nutrition $\cdot$ Policy integration $\cdot$ Integrated nutrition strategies $\cdot$ Uganda $\cdot$ Governance

\section{Introduction}

To tackle malnutrition more effectively, many Sub-Saharan African (SSA) governments have developed overarching integrative policy strategies over the past decade (Candel 2018). Malnutrition refers to a range of nutrition disorders, whereby a common distinction is made between undernutrition and overnutrition (Webb et al. 2018; WHO 2013). The recent emergence of integrated nutrition strategies (INSs) seems to indicate political commitment to sustain global efforts towards

Electronic supplementary material The online version of this article (https://doi.org/10.1007/s12571-020-01010-5) contains supplementary material, which is available to authorized users.

Brenda Shenute Namugumya

brenda.namugumya@wur.nl

1 Public Administration and Policy Group, Wageningen University \& Research, Hollandseweg 1, 6706KN Wageningen, Netherlands

2 Division of Human Nutrition and Health, Wageningen University \& Research, Stippeneng 4, 6708WE Wageningen, Netherlands nutrition improvements and sustainable development more broadly (Gillespie et al. 2015; Nisbett et al. 2014a; Acosta and Fanzo 2012). These strategies typically transcend the boundaries of policy sectors (IFPRI 2016; WHO 2013; Fan and Pandya-Lorch 2012; Garrett and Natalicchio 2011) and are often developed in close collaboration with international organisations and donors. The assumption underlying INSs is that such cross-sectoral action is required to tackle the multidimensional causes and effects of malnutrition (Reinhardt and Fanzo 2014; Ruel and Alderman 2013). For that reason, INSs generally prescribe the integration of nutrition concerns across the policy outputs of relevant government sectors, such as health, agriculture, social development, education, and trade.

Despite the recent popularity of INSs, to date little is known about their follow-up and, ultimately, success (or failure) over time. Although these overarching policy strategies may be key in putting nutrition on the political agenda, they largely serve a symbolic and agenda-setting function (cf. Candel and Pereira 2017). For integrated government action to occur, their objectives and proposals would have to be integrated into regular policy outputs of relevant ministries (cf. Cejudo and Michel 2017). Policy outputs refer to the 
programmes, laws, or regulations that result directly from the decision-making processes in these sectors (Knill and Tosun 2012). Food and nutrition security scholars have provided valuable insights into changes in nutrition-related policies and institutions (e.g. Pelletier et al. 2017; Kampman et al. 2017; Hodge et al. 2015; Pomeroy-Stevens et al. 2016; Lachat et al. 2015; Mogues and Billings 2015; Benson 2008), but few systematic studies have been performed on the actual integration of nutrition across relevant sectors' policy outputs (but see: Harris et al. 2017). Additionally, most studies have focused on single sectors or interventions (e.g. Lachat et al. 2015; Hodge et al. 2015), and this does not allow for obtaining a comprehensive understanding of the whole of government actions. Consequently, it remains an open question whether the adoption of these ambitious overarching nutrition strategies has been followed up by genuine policy integration processes. Apart from filling this gap in the scientific literature, such an understanding would be essential to assess the extent to which international calls to sustain nutrition improvement efforts have been followed up.

To address this gap, this study addresses the question of the extent to which nutrition has been integrated into policy outputs developed over time by different ministries. We analyse the case of Uganda, a SSA country with a relatively long tradition of - and a well-established reputation for - developing integrated nutrition policies. Uganda has invested in overarching integrated nutrition strategies since 1996 (FAO 2002; Bachou and Labadarios 2002) to address malnutrition, which remains largely prevalent (UBOS 2012; UBOS and ICF 2018). These strategies include the 1996 Uganda National Plan of Action for Nutrition (UNPAN), the 2003 Uganda Food and Nutrition Policy (UNFP), and the Uganda Nutrition Action Plan (UNAP) 2011-2016. The development and adoption of these strategies were largely driven by various global initiatives (Harris 2019; Pelletier et al. 2017), such as the World Food Summit (FAO 2002), the Scaling Up Nutrition Movement (SUN) (SUN 2010), and the second International Conference on Nutrition (ICN2) (FAO and WHO 2014). The UNPAN was adopted by the Ministry of Health, the UNFP was jointly adopted by the health and agriculture ministries, and the UNAP was approved with highlevel political affirmation from the president and several ministers. This was followed by the assignment of the Office of the Prime Minister to coordinate its implementation - an action that may have resulted in broader policy integration.

To understand whether Uganda's adoption of INSs has indeed been followed up by processes towards integrated government action, we use a modified version of a recently developed policy integration framework that approaches policy integration as a multi-dimensional process (Candel and Biesbroek 2016). The framework allows the systematic tracking of how a crosscutting concern, here (mal)nutrition, has been (dis)integrated across policies over time. In this study, we use the framework to analyse a dataset consisting of policy outputs adopted by eight ministries over four election cycles from 2001 to 2017. Apart from addressing an important gap in the food and nutrition security literature, the study is also of value to the policy sciences, which have only recently turned their attention to policy change in developing country contexts. Importantly, our analysis is restricted to policy integration across policy outputs. Whether or not policy integration across policy outputs results in a change in policy outcomes, i.e. policies as implemented, will be assessed in a follow-up study.

The paper proceeds with a concise explanation of the policy integration framework. Section 3 sets out the methodological approach, including data collection, analysis, and limitations. Section 4 presents the study's findings. The paper ends with a discussion, in which we set out various policy recommendations and future research avenues.

\section{A multi-dimensional policy integration framework}

Policy integration refers to the extent to which a governance system addresses a crosscutting concern in a more or less holistic manner across sectors and, possibly, levels (Tosun and Lang 2017). Whereas many policy integration scholars approach the concept as a (desired) outcome or governing principle (e.g. Jordan and Lenschow 2010; Persson 2006; Lafferty and Hovden 2003), we adopt a framework recently developed by (Candel and Biesbroek 2016) that considers policy integration as a process over time. This framework starts from four assumptions:

(i) Policy integration is as much about disintegration as it is about advances in integration;

(ii) Policy integration is a process that encompasses various dimensions;

(iii) These dimensions do not necessarily move at the same pace, or even in the same direction;

(iv) At the same time, mutual dependencies and interactions occur between dimensions. However, these remain understudied at present.

The four dimensions of policy integration that the framework distinguishes are: policy frame, subsystem involvement, policy goals, and instruments. Whereas policy frame refers to the instutionalization of governance beliefs within a polity, this study is restricted to the latter three, policy-oriented variables, which are further divided into two or more indicators. Additionally, although the original framework includes the coherence of goals and the consistency of instruments as indicators, we did not assess 
these because currently there are no methods for doing so (Candel and Biesbroek 2016).

The subsystem involvement dimension refers to the range of actors and institutions, both public and private, that are actively dealing with a crosscutting policy issue, such as malnutrition (Howlett and Ramesh 2003; Sabatier 1998). Different from (Candel and Biesbroek 2016; 2018), we approach subsystems involved as the number of ministries involved in nutrition governance as well as associated networks of actors with which they interact. We cluster these interacting actors into (other) ministries, international organisations and donor governments, NGOs, and forprofit organisations. For a low degree of policy integration, one would expect a 'siloed' way of working, in which malnutrition is dealt with by only a single ministry and associated subsystem. For a high degree of integration, malnutrition concerns would be integrated into the policy outputs of all relevant ministries, which would have developed, and interacted with, actor networks of their own.

The policy goals dimension involves the range of sectoral policies that explicitly incorporate nutrition goals as well as the dimensions of malnutrition that these target (Candel and Biesbroek 2018). In the former case, the nutrition literature distinguishes between nutrition-specific and nutritionsensitive policies (Webb et al. 2018; Reinhardt and Fanzo 2014; Ruel and Alderman 2013). We consider a policy output to be either nutrition specific or sensitive only when an explicit reference is made to (mal)nutrition. The second indicator falling under this dimension, which we have added to the framework, relates to the dimensions of malnutrition that are being targeted. As the problem of malnutrition encompasses many aspects at individual, household, and societal level, goals can be either narrow or broad in scope. For a low degree of policy integration, malnutrition concerns would be integrated in only one or a few policies of a dominant ministry. In addition, we would expect only a limited number of determinants of malnutrition to be addressed. For a high degree of policy integration, one would observe policy goals aligned with nutrition concerns in all relevant policies across sectors, whereby all determinants of malnutrition would be addressed by one or more policies.

The policy instruments dimension comprises the extent to which sectoral policies include the means to realise nutrition objectives. Public policy scholars have developed various frameworks to cluster different types of instruments. Here, we adopt Hood (1983)'s popular NATO framework, which clusters instruments based on four 'governing resources' that governments may use to steer: nodality (information), authority, treasure, and organisation. In addition, we distinguish between substantive and procedural instruments. Substantive instruments use these governing resources to directly affect the 'nature, types, quantities and distribution of the goods and services provided in society', whereas procedural instruments are designed to 'indirectly affect outcomes through the manipulation of policy processes' (Howlett 2000; p. 413). Examples of substantive instruments are food aid, nutrition guidelines, and grants to farmers. Examples of procedural instruments are inter-departmental committees, constitutional provisions, and strengthening human capacity within ministries. As we focus on the integration of nutrition across sectors, we analysed the use of such instruments within ministries. Importantly, although many instruments may impact nutrition in some way or even be classified as nutrition sensitive, we only consider these nutrition policy instruments if they are explicitly linked to nutrition concerns and/or goals. For a low degree of policy integration, we would expect instruments to be restricted to a single sector and calibrated towards a limited number of nutrition goals. There would be no or few procedural instruments within that sector. A high degree of policy integration is characterised by all relevant sectors explicitly aligning one or more instruments with nutrition goals, so that the governance system as a whole possesses an instrument mix that enables the realisation of overarching objectives. In addition, there would be procedural instruments within ministries that enable coordination, implementation, evaluation, and so forth.

Table 1 provides an overview of the dimensions and indicators that we used. This table is adopted from a previous study on the integration of global food security concerns into European Union policies (Candel and Biesbroek 2018) and tailored to the Ugandan nutrition governance context. Thus, the table presents ideal-type manifestations of different degrees of the dimensions in Ugandan nutrition governance. In between no, and the highest degree of, policy integration, we distinguish two intermediate degrees, i.e. low and medium degrees of policy integration.

\section{Methodology}

\subsection{Data collection}

We performed a qualitative content analysis of policy outputs adopted between 2001 and 2017. The ministries that we considered as relevant are those that signed the UNAP, i.e. the ministries of (i) Health (MOH), (ii) Agriculture, Animal Industry, and Fisheries (MAAIF), (iii) Gender, Labour, and Social Development (MGLSD), (iv) Education and Sports (MoES), (v) Trade, Industry, and Cooperatives ${ }^{1}$ (MTIC), (vi) Local Government (MoLG), (vii) Finance, Planning, and Economic Development (MoFPED), and (viii) the Office of the Prime

\footnotetext{
${ }^{1}$ Until 2010, this ministry was called the Ministry of Tourism, Trade, and Industry.
} 


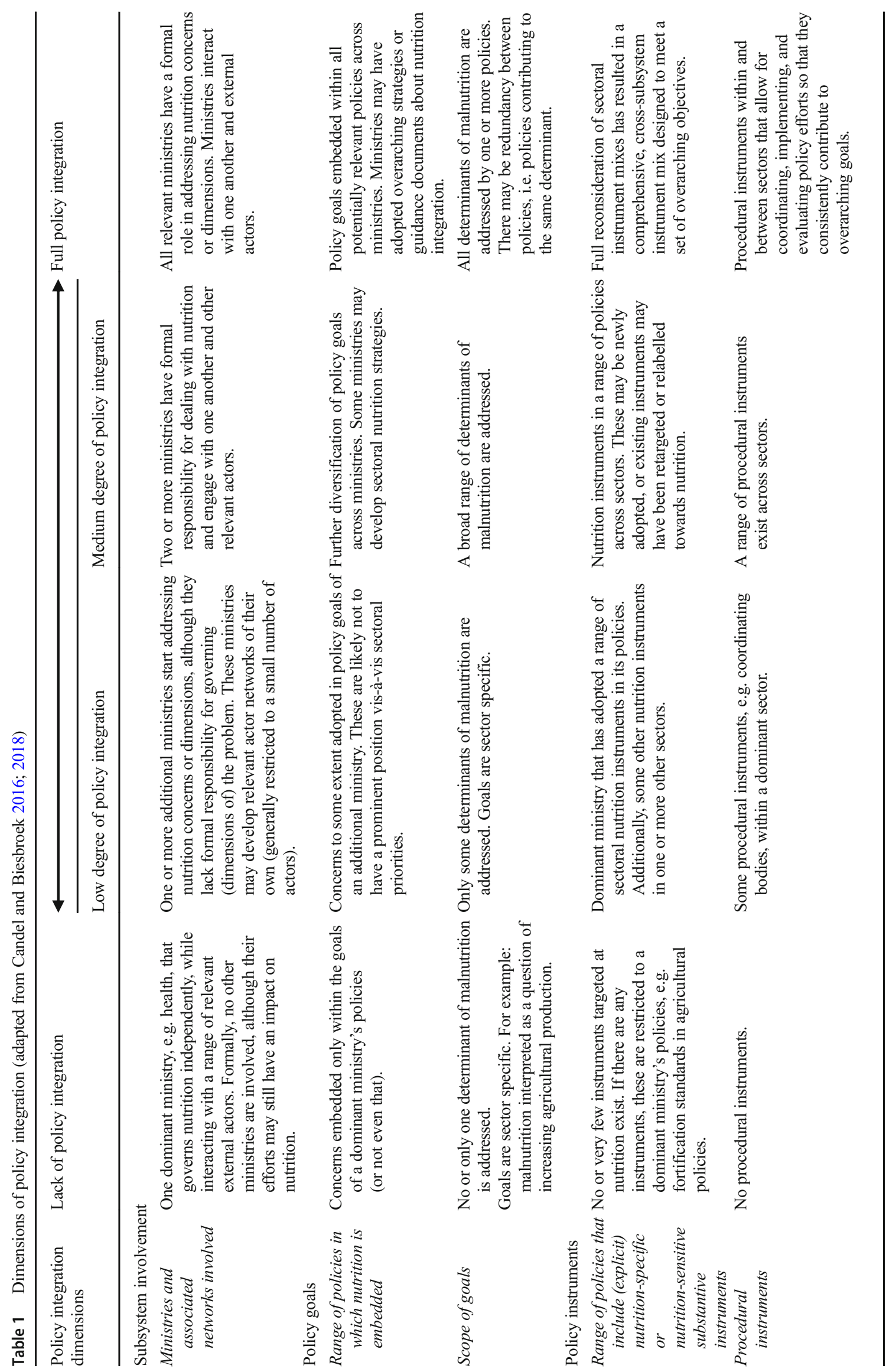




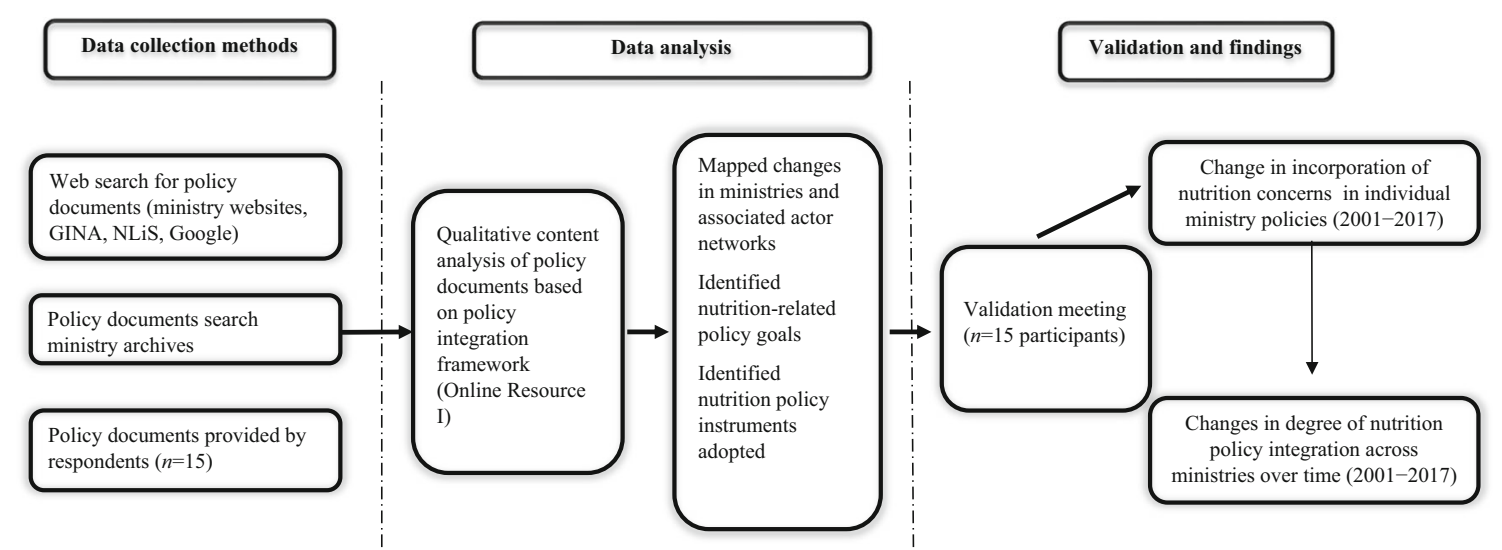

Fig. 1 Summary of method

Minister (OPM). The Ugandan 2009 Comprehensive Planning Framework requires all ministries to align their policy outputs with National Development Plans' priorities, including nutrition. We analysed the extent to which they did so by looking at three types of policy outputs: (i) the overarching ministerial policies that set out ministries' strategic objectives over a fiveyear period, (ii) sector strategic plans that propose interventions to realise each sector's policy objectives, and (iii) ministerial policy statements, which summarise annual sector performance and future expenditure plans. Ministerial policy statements are presented annually to parliament for approval of the budget. Figure 1 provides a summary of our study methodology.

Policy documents were collected in three ways. First, we performed a comprehensive online search of ministry websites and global databases covering nutrition policies, including the World Health Organisation Global Database on the Implementation of Nutrition Action (GINA) and the Nutrition Policy Landscape Information System (NLiS). Second, we searched the archives of ministries. Third, we interviewed people working in ministries, non-governmental organisations, and academia between December 2017 and April 2018 to access additional documents. In total, we analysed 103 policy documents, listed in Online Resource 1. Because the actors with which ministries interacted over time were not consistently included in policy outputs, we used the interviews and a workshop (see below) to complement these.

\subsection{Data analysis}

We clustered the policy documents into four periods between 2001 and 2017 based on Uganda's election cycles (2001-2005; 2006-2010; 2011-2015; 2016-2017). Even though Uganda has had the same president since the late 1980s, elections are usually followed by cabinet reshuffles, a restructuring of institutions and changes of political prioritizations (cf. Jones and Baumgartner 2004).

This allowed comparison of changes in degrees of policy integration over time. Documents were coded using the program Atlas.ti. We developed codes deductively, drawing upon discussions of nutrition-specific and nutrition-sensitive interventions in the nutrition literature (Webb et al. 2018; Ruel and Alderman 2013; Black et al. 2013), and supplemented these with inductively developed codes. Coding of policy documents was done by the first author and a research assistant. The other authors were involved in the coding process to resolve different possible interpretations. For subsystems, we identified the actors interacting with the ministries from references made to these actors in policy documents and interview data. We only coded goals that made explicit reference to nutrition or malnutrition to allow for comparison across ministries and time periods. For instruments, we only coded the interventions that had the explicit aim of improving (mal)nutrition. Subsequently, we clustered similar types of interventions into nine broad instrument categories (Online Resource 2). Whereas the nutrition-related goals and associated actors were mentioned in all three types of policy outputs, information about policy instruments was primarily presented in ministerial policy statements. We extracted relevant quotations into a data extraction matrix (Online Resource 3). The table served as point of departure for writing the synthesis, for which we analysed it along the dimensions and indicators provided in Table 1. To validate our findings, a workshop was organised in Kampala in May 2018. The workshop was attended by 15 participants representing government, NGOs, and academic staff. We asked participants to provide feedback on: (i) whether we had missed any relevant documents, (ii) the actors involved in nutrition governance, and (iii) our preliminary synthesis.

\subsubsection{Limitations}

Our research design is subject to various limitations. First, as government documents are not systematically digitalised, we may have missed documents. We minimised this risk by using different methods for document collection and consultation with stakeholders in a workshop to validate the inclusion of all critical documents. Second, some policy documents, such 
as strategic plans and overarching sector policies, overlapped across the election analysis cycles. We considered the year of adoption as informing placement in the election cycle. For example, as the National Agriculture Policy is the only overarching policy adopted by the ministry, its year of adoption (2013) informed its placement in the election cycle for analysis. Third, our focus on policy outputs explicitly linked to nutrition implies that we did not look into unintentional policies that may indirectly affect nutrition outcomes (cf. Dupuis and Biesbroek 2013).

\section{Results}

The study findings are presented in two sections. The first section provides a detailed account of nutrition integration within each ministry over time. The underlying data are provided in Online Resource 3 for each ministry. In the second section, we synthesise these insights to distil the overarching patterns of nutrition integration.

\subsection{Integration of nutrition in specific ministries}

\subsubsection{Office of the Prime Minister (OPM)}

OPM participation in the nutrition agenda started in 2006. This was followed by an increase in external actors interacting with the sector, especially during cycle 3 (2011-2015), see Fig. 2. Whereas the ministries collaborating with OPM remained similar throughout the analysis period, we observed a rise in the number of international agencies and partner countries between 2011 and 2017. These actors contributed both technical ideas and financial assistance to advance OPM's nutrition policy coordination efforts.

The number of nutrition-related goals in OPM policy outputs increased somewhat in the period 2011-2015, before declining in 2016. Improving food and nutrition security in disaster-prone regions was the prevailing goal since 2006; this is attributable to the specific region-focused programmes managed by OPM. From 2011 onwards, goals expanded to the coordination of the scaling up of nutrition interventions and developing an enabling nutrition policy environment.

For instruments, a similar trend can be observed: the range of instruments used by OPM increased considerably in the period 2011-2015, but decreased again in 2016-2017 (Table 2). The provisioning of food aid during disasters was a key substantive instrument used throughout the analysis period. From 2011 onwards, we observed the emergence of various procedural instruments, including the multisector nutrition committee, national nutrition forum, and capacity building for sector and district nutrition committees. The creation of a UNAP coordination desk in OPM's Policy Implementation and Coordination department in 2012 reinforced its engagement in nutrition. OPM mainly compiled reports that monitored and evaluated government performance for the period 2001-2005. We could not reconstruct OPM's sectoral goals and instruments.

\subsubsection{Ministry of Health $(\mathrm{MOH})$}

Prior to 2011, nutrition policy in Uganda was dominated by $\mathrm{MOH}$. During this period, $\mathrm{MOH}$ developed a wide actor network, which remained largely similar in size. However, the types of actors with which the ministry interacted varied over time. For example, $\mathrm{MOH}$ collaborated with many international agencies or partner countries (e.g. UNICEF, USAID, WHO, GAIN) and non-government organisations during the 2006-2010 period compared to other years. The period 2016-2017 saw a decline in the number of actors interacting with the ministry.

Between 2001 and 2015, MOH's nutrition-related policy goals increased in number and scope of determinants addressed. However, these decreased again in 2016-2017 policy outputs. The sector consistently aimed to reduce maternal and child undernutrition. The scope of specific objectives to realise these goals included addressing micronutrient deficiencies and nutrition response in emergencies (2001-2005), which expanded to integration into health service delivery (2006-2010) towards scaling up coverage and diversity of nutrition services offered in health delivery systems (2011-2015).
Fig. 2 Actors involved in nutrition governance between 2001 and 2017

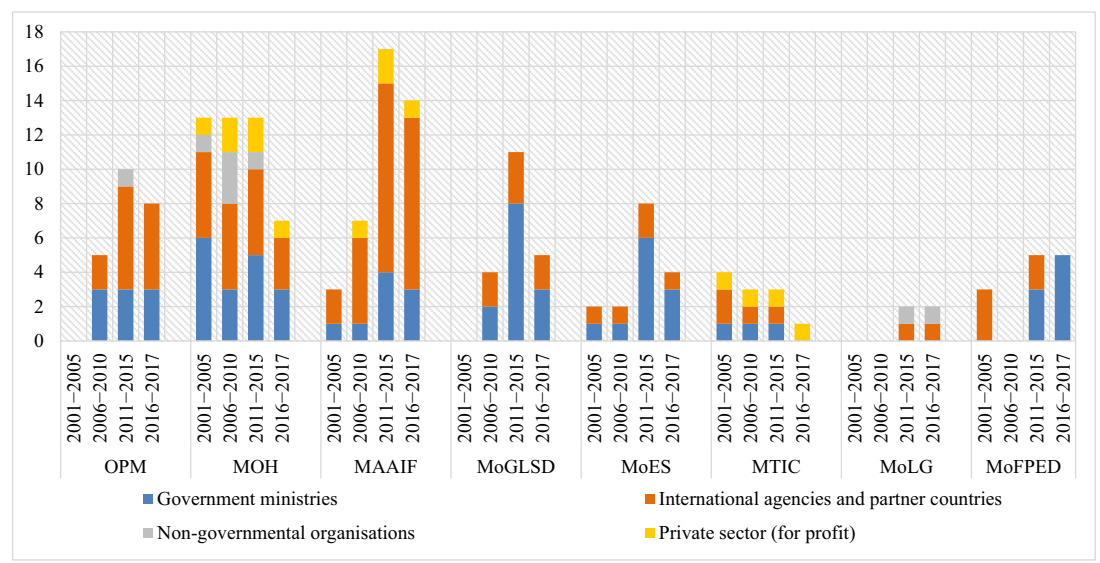




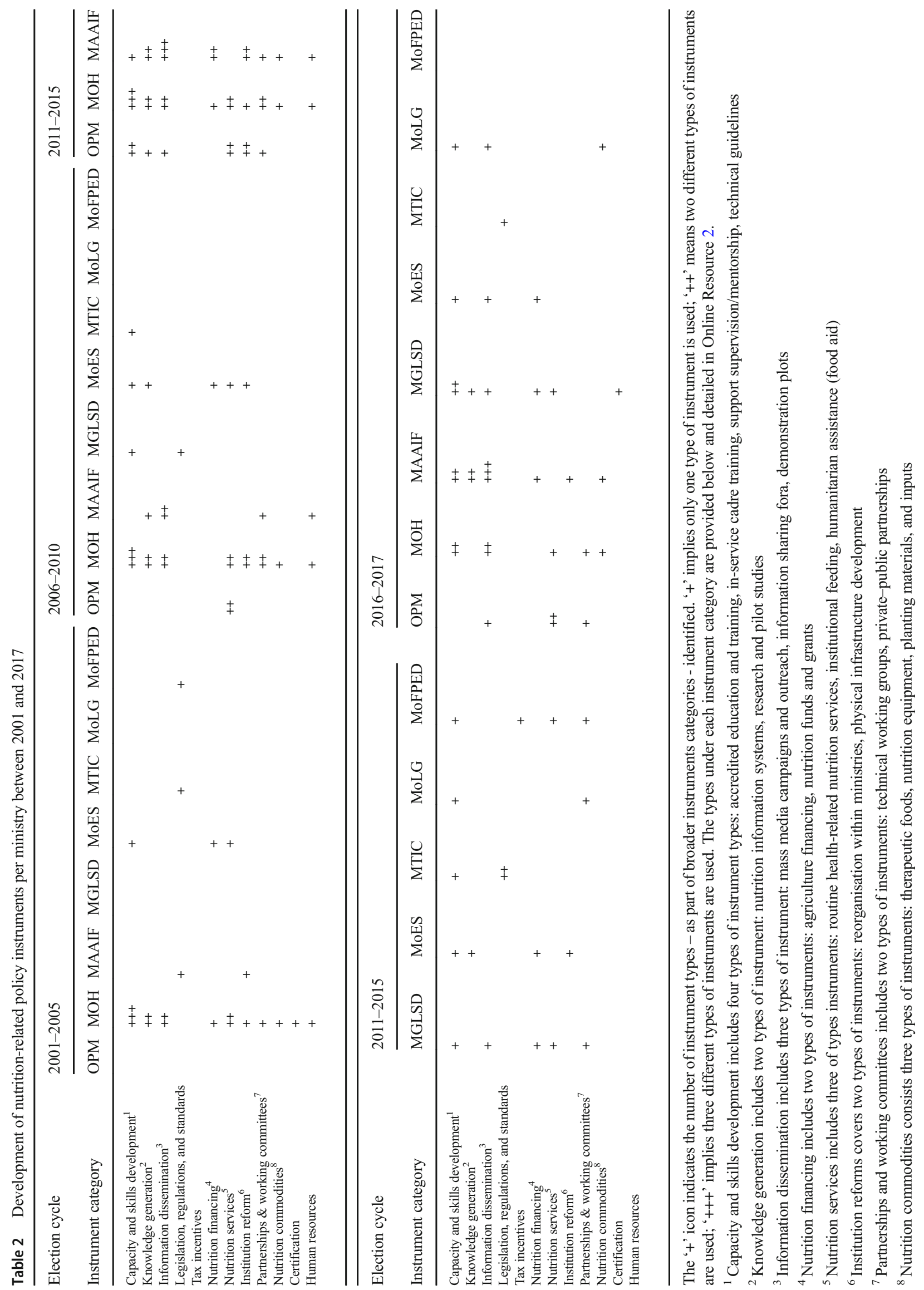


In terms of instruments, MOH deployed a diverse mix between 2001 and 2015. These spread across the majority of category types highlighted in Table 2 . MOH continuously broadened the scope of nutrition concerns addressed with these instruments. Some key instruments deployed include nutritionist positions in hospitals, upgrading the nutrition unit to a division, expanding nutrition indicators in the health information system, and various technical guidelines that became redefined in this period to strengthen $\mathrm{MOH}$ nutrition efforts. Until 2011, only MOH made use of nutrition working groups. As was the case with goals, the number of instruments declined considerably in the last cycle.

\subsubsection{Ministy of Agriculture, Animal Industry and Fisheries (MAAIF)}

MAAIF has traditionally been actively engaged in Uganda's food and nutrition security policies. We observed an incremental growth in MAAIF's actor network across the analysis period, especially during 2011-2015. Whereas growth occurred across all actor categories, Fig. 2 shows that it was most evident among international agencies and partner countries from 2006 to 2010 onwards. Recurring liaisons existed with traditional agencies such as USAID, FAO, the World Bank, and the European Union, complemented with new types of actors, e.g. for-profit organisations, after 2011.

The overarching nutrition-related aim incorporated in MAAIF policy outputs since 2001 is improved household food and nutrition security, but explicit nutrition-focused goals increased numerically and diversified in scope from 2011 to 2015 onwards. For example, goals in 2011-2015 focused on food and nutrition security surveillance, proactive nutrition planning, and research on nutrient-dense crops, and after 2016 expanded to include food safety, value addition, and nutrition training for extension workers. Almost all explicit nutrition goals in MAAIF policy outputs concentrate on micronutrient density in crops and associated value chains.

The nutrition instruments applied in MAAIF increased in number, especially between 2011 and 2017. Traditionally used instruments, e.g. commissioned research on nutrient-dense crops and information fora, were complemented with seven new instruments in 2011-2015. These included information instruments (technical guidelines, information systems, accredited training of agriculture officers); organisation instruments (nutrition division, coordination committee), and financial instruments (GAFSP grant). Instruments incorporated in 2016-2017 policy outputs remained comparable to those in 2011-2015.

\subsubsection{Ministry of Gender, Labour and Social Development (MGLSD)}

MGLSD started participating in nutrition agendas in 20062010. Its involvement became particularly prominent from
2011 to 2015 onwards. Figure 2 shows that the external actors assisting the sector broadened in this period to include other ministries and international agencies, including UNICEF, USAID, Irish Aid, and ICEIDA.

This ministry's policy outputs did not integrate explicit nutrition goals until 2011-2015. During this period, the number nutrition goals increased substantially and also expanded in terms of their scope. In addition to the consistent goals of improving household food and nutrition security, we observed that the usual MGLSD programmes like community mobilisation, early childhood development, and social protection also began to include nutrition objectives.

The range of nutrition instruments used increased from 2006 to 2010 onwards. MGLSD deployed seven new instruments between 2011 and 2017. The ministry also introduced the Employment Act 2006, which permitted maternity and paternity leave to promote child care and protection. Table 2 shows that this ministry used a mix of substantive and procedural instruments with nutrition goals, including information instruments (technical guidelines, training community development officers, and media campaigns); financial instruments (social protection grants); and organisation instruments (sector nutrition coordination committee).

\subsubsection{Ministry of Education and Sports (MoES)}

MoES was involved in nutrition agendas throughout the whole analysis period. The sector's external actor network remained the same until 2011-2015, when the number of actors increased. However, this decreased again in 2016-2017, see Fig. 2. Our analysis shows that the World Food Programme (WFP) supported MoES' school feeding programme in 2001-2010. The main actors supporting the ministry's nutrition initiatives in recent years are UNICEF and the World Bank/GAFSP. MoES collaborated with $\mathrm{MOH}$ and MAAIF over the whole period.

Explicit nutrition-related goals emerged in MoES policy outputs only from 2006 to 2010 onwards. Whereas the number of goals remained largely the same, variation existed in the scope addressed. During the 2006-2010 period, the emphasis was on the general nutrition and health status of school children and developing novel food processing and nutrition enterprises. The latter goal prevailed in 2011-2015 alongside the requirement for a school feeding policy. Sensitising communities on school feeding was the only goal targeted during the period 2016-2017.

We observed that MoES incorporated nutrition instruments throughout the whole analysis period. The number of instruments increased slightly between 2006 and 2015, followed by a reduction in 2016-2017. Instruments used across the entire study period include the accreditation of programmes and training grants for nutrition cadres. MoES deployed various information instruments over time, e.g. research and pilot studies (20062010), technical guidelines on school feeding (2011-2015), and mass media campaigns (2016-2017). The majority of the 2006- 
2010 instruments were dropped by 2016-2017, except for accredited programmes and the training of nutrition cadres.

\subsubsection{Ministry of Trade, Industry and Cooperatives (MTIC)}

MTIC has participated in Uganda's nutrition policies, especially the food fortification agenda, from before 2001. Despite this long-standing engagement in nutrition, its associated actor network remained small across the study period (see Fig. 2). The MTIC nutrition network comprised mainly for-profit organisations and $\mathrm{MOH}$. Over time, various international organisations have given financial and technical assistance to undertake the fortification mandate, including UNICEF (20012005), GAIN (2006-2010), and USAID (2011-2015).

Unlike other ministries, the MTIC policy outputs did not include any explicit (mal)nutrition-related goals. The ministry did deploy various nutrition instruments, which remained similar in type and number across the study period. Instruments consistently deployed throughout this period include the Food and Drugs (food fortification) regulations 2005 (amended in 2011), capacity building for inspectors, and various food standards focusing on food safety, quality, and public health standards.

\subsubsection{Ministry of Local Government (MoLG)}

MoLG was the last sector to attend to the nutrition improvement agenda, joining in 2011-2015 (see Fig. 2). The sector's external actor network in nutrition remained small, despite its mandate to coordinate district level operations. USAID and the Islamic Development Bank supported MoLG between 2011 and 2015. For the most recent years, only the latter was mentioned.

The first explicit nutrition goal emerged in MoLG policy during 2011-2015. The goals slightly increased in number in 2016-2017 policy outputs. We observed that the goals expanded from integrating nutrition concerns in district plans and budgets (2011-2015) to more abstract aims such as implementing the food and nutrition policy (2016-2017).

Similar to the goals, MoLG's nutrition instruments were first introduced in 2011-2015 and diversified in 2016-2017. Between 2011 and 2015, the sector established an interdepartmental nutrition committee and trained districts in nutrition planning. Instruments broadened in 2016-2017 to include the provisioning of nutrient-dense planting materials and mass media campaigns and outreaches.

\subsubsection{Ministry of Finace, Planning and Economic Development (MoFPED)}

Despite MoFPED being among the nutrition actors during 20012005, Fig. 2 indicates that efforts to re-engage in nutrition actions only resurfaced from 2011 onwards. Generally, the external actors supporting nutrition in MoFPED increased in 2011-2015 but reduced considerably afterwards. During the period 20112015, MoFPED spearheaded the processes of developing the UNAP and the national nutrition planning guidelines in liaison with international agencies like USAID, WFP, and the International Food Policy Research Institute. However, the actor network in 2016-2017 comprised only other ministries.

Halving malnutrition by 2015 was the only nutritionrelated goal incorporated in the MoFPED Poverty Eradication Action Plans compiled in 2001-2005. Our analysis revealed a considerable rise in the number and scope of nutrition goals in the national development plans (NDPs) endorsed between 2011 and 2017, despites their absence from the policy outputs for the period 2006-2010. MoFPED is responsible for compiling and monitoring the NDPs. The nutrition goals in the NDPs generally reflected those promoted in the policy outputs of MOH, MAAIF, MGLSD, and MoES.

The MoFPED instruments explicitly targeting nutrition were first mentioned in 2011-2015. The ministry deployed a mix of financial and information instruments, such as tax exemptions on food fortification inputs, declared nutrition a crosscutting planning and budgeting issue, and developed the nutrition planning guidelines. In the same period, a key procedural instrument applied was the multisector nutrition forum that developed the UNAP. No specific instruments were identified in MoFPED's policy outputs of 2016-2017. This may be attributable to the fact that nutrition goals in the NDP are addressed mainly by the technical sectors, which already elaborate specific instruments in their policy outputs.

\subsubsection{Overall patterns of nutrition integration}

Table 3 shows the overarching patterns of nutrition policy integration in Uganda between 2001 and 2017 based on the findings per ministry presented in section 4.1. The assessment revealed a gradual shift towards higher degrees of nutrition policy integration in all the dimensions. However, there are fundamental differences in the degrees of policy integration realised among the dimensions over time. Over the period 2001-2005, the degree of policy integration for nutrition was generally low across all the dimensions. Regarding the subsystems involved, the nutrition policy agenda was primarily dominated by $\mathrm{MOH}$, which collaborated with an extensive external actor network. Other sectors, especially MAAIF and MTIC, made some minimal policy contributions. Three sectors (MOH, MAAIF, and MoFPED) highlighted at least one goal to improve undernutrition. The range of instruments was restricted and mainly embedded within the dominant subsystem surrounding $\mathrm{MOH}$, which addressed some but not all determinants of nutrition.

Between 2006 and 2010, we observe some shifts towards higher degrees of policy integration for subsystems involved, but low degrees persisted for the goals and instruments. Policies of all ministries, except MoLG and MoFPED, highlighted nutrition concerns. $\mathrm{MOH}$ continued to be the 
Table 3 Patterns of nutrition policy integration between 2001 and 2017

\begin{tabular}{|c|c|c|c|c|}
\hline $\begin{array}{l}\text { Policy } \\
\text { integration } \\
\text { dimensions }\end{array}$ & $2001-2005$ & 2006-2010 & 2011-2015 & 2016-2017 \\
\hline \multicolumn{5}{|c|}{ Subsystem involvement } \\
\hline $\begin{array}{l}\text { Ministries and } \\
\text { associated } \\
\text { networks } \\
\text { involved }\end{array}$ & $\begin{array}{l}\text { Level II } \\
\text { MOH, MAAIF, MoES, } \\
\text { MTIC, MoFPED }\end{array}$ & $\begin{array}{l}\text { Level III } \\
\text { MOH, MAAIF, MGLSD, } \\
\text { MoES, MTIC, OPM }\end{array}$ & $\begin{array}{l}\text { Level IV } \\
\text { Nutrition issues in OPM } \downarrow, \text { MOH } \downarrow \text {, } \\
\text { MAAIF } \uparrow, \text { MGLSD } \uparrow, \text { MoES, } \\
\text { MTIC } \downarrow, \text { MoLG, MoFPED } \downarrow\end{array}$ & $\begin{array}{l}\text { Level IV } \\
\text { Nutrition issues in OPM } \downarrow \text {, MOH } \downarrow \text {, } \\
\text { MAAIF } \uparrow, \text { MGLSD } \uparrow, \text { MoES, } \\
\text { MTIC } \downarrow, \text { MoLG, MoFPED } \downarrow\end{array}$ \\
\hline \multicolumn{5}{|l|}{ Policy goals } \\
\hline $\begin{array}{l}\text { Range of policies } \\
\text { in which } \\
\text { nutrition is } \\
\text { embedded }\end{array}$ & $\begin{array}{l}\frac{\text { Level II }}{\text { Nutrition goals in MOH, }} \\
\text { MAAIF, MoFPED. } \\
\text { Only MOH specific } \\
\text { nutrition goals }\end{array}$ & $\begin{array}{l}\frac{\text { Level II }}{\text { Nutrition goals in MOH, }} \\
\text { MAAIF, OPM, MoES. } \\
\text { Only MOH specific } \\
\text { nutrition goals }\end{array}$ & $\begin{array}{l}\frac{\text { Level III }}{\text { Goals included in all ministries }} \\
\text { OPM } \uparrow, M O H \uparrow, \text { MAAIF } \uparrow \\
\text { MGLSD } \uparrow, \text { MoES } \downarrow, \text { MoLG, } \\
\text { MoFPED } \uparrow, \text { except MTIC }\end{array}$ & $\begin{array}{l}\frac{\text { Level III }}{\text { Goals included in all ministries }} \\
\text { OPM } \downarrow, \text { MOH } \downarrow, \text { MAAIF } \uparrow, \\
\text { MGLSD } \uparrow, \text { MoES } \downarrow, \text { MoLG } \downarrow \text {, } \\
\text { MoFPED, except MTIC }\end{array}$ \\
\hline Scope of goals & $\begin{array}{l}\text { Level I } \\
\text { Some determinants of } \\
\text { undernutrition covered } \\
\text { in } \mathrm{MOH}\end{array}$ & $\begin{array}{l}\text { Level II } \\
\text { Some determinants of } \\
\text { undernutrition in } \mathrm{MOH} \text {, } \\
\text { MAAIF }\end{array}$ & $\begin{array}{l}\text { Level II } \\
\text { Some determinants of undernutrition } \\
\text { specific to sectors covered }\end{array}$ & $\begin{array}{l}\text { Level II } \\
\text { Some determinants of undernutrition } \\
\text { specific to sectors covered }\end{array}$ \\
\hline \multicolumn{5}{|c|}{ Policy Instruments } \\
\hline $\begin{array}{l}\text { Range of policies } \\
\text { that include } \\
\text { substantive } \\
\text { instruments }\end{array}$ & $\begin{array}{l}\text { Level II } \\
\text { Mainly in MOH, few } \\
\text { instruments in MAAIF, } \\
\text { MoES, MTIC, } \\
\text { MGLSD, MoFPED }\end{array}$ & $\begin{array}{l}\text { Level II } \\
\text { Mainly in MOH, few } \\
\text { instruments in MAAIF, } \\
\text { MoES, MGLSD, OPM, } \\
\text { MTIC }\end{array}$ & $\begin{array}{l}\text { Level III } \\
\text { Instruments in OPM, MOH, } \\
\text { MAAIF, MGLSD, MoES, MTIC, } \\
\text { MoFPED } \\
\text { New instruments and relabelling } \\
\text { some existing ones }\end{array}$ & $\begin{array}{l}\text { Level III } \\
\text { Instruments in OPM, MOH, } \\
\text { MAAIF, MGLSD, MoES, MTIC } \\
\text { New instruments adopted }\end{array}$ \\
\hline $\begin{array}{l}\text { Range of policies } \\
\text { that include } \\
\text { procedural } \\
\text { instruments }\end{array}$ & $\begin{array}{l}\text { Level II } \\
\text { Nutrition working group } \\
\text { in } \mathrm{MOH}\end{array}$ & $\begin{array}{l}\text { Level II } \\
\text { Nutrition working groups } \\
\quad \text { in MOH, MAAIF }\end{array}$ & $\begin{array}{l}\text { Level III } \\
\text { OPM assigned overall nutrition } \\
\text { coordination mandate } \\
\text { Sector committees for nutrition } \\
\quad \text { MOH, MAAIF, MGLSD, MoLG }\end{array}$ & $\begin{array}{l}\text { Level III } \\
\text { OPM assigned overall nutrition } \\
\text { coordination mandate } \\
\text { Sector committees for nutrition } \\
\quad \text { MOH, MAAIF, MGLSD, MoLG }\end{array}$ \\
\hline
\end{tabular}

Level I denotes no policy integration; Level II denotes low degree of policy integration; Level III denotes medium degree of policy integration; Level IV denotes full policy integration

$\uparrow$ denotes an increase in either number of external actors or number of goals; $\downarrow$ denotes a decrease in either number of external actors or number of goals.

dominant subsystem in nutrition and liaised with a range of other ministries, international agencies, and partner countries. However, the increase in subsystems in nutrition policy was not matched with substantial changes in the scope of nutrition goals. Conversely, the number of nutrition instruments increased slightly and their scope expanded somewhat. Yet, similar to the period 20012006, a majority of the instruments remained embedded within the dominant subsystem and addressed some but not all determinants of nutrition. There were no crosssector coordinating instruments.

All ministries analysed deliberately strove to advance the nutrition policy agenda in some way between 2011 and 2015. Full policy integration was realised for subsystems involved, and shifts towards higher degrees of integration were found for the goals and instruments. During this period, nutrition became a crosscutting planning concern, a result of which an expansion to all eight ministries occurred. Each ministry received technical and financial support from one or more international agencies or partner countries. Nutrition goals increased in number and diversified in scope, although they addressed mainly determinants of maternal and child undernutrition or food and nutrition insecurity (see Online Resource 3) and often appeared as parallel project initiatives in most ministries. MTIC did not integrate explicit nutrition goals. Goals related to overweight and diet-related non-communicable diseases were absent. In terms of the instruments targeting nutrition, this period was characterised by the largest introduction of new tools. Most of these tools drew upon information and organisation, whereas the use of financial and regulatory instruments remained limited. In addition, procedural instruments to coordinate across sectors came into use with OPM at the helm.

For the last analysis period (2016-2017), the degree of policy integration realised across the dimensions was largely similar to that in the previous period. However, there was a general decline in support from international agencies and partner countries. Further, the number and scope of goals and instruments decreased in some ministries, such as $\mathrm{MOH}$, MoES, and OPM. 


\section{Discussion}

\subsection{Reflection on the results}

This paper started with the observation that tracking political commitment to malnutrition has gained global interest and various approaches have been applied to understand progress across countries (e.g. HANCI 2017; IFPRI 2016; Fox et al. 2015; WHO 2013). Our analysis adds to this debate by using a novel policy integration approach to address the question of the extent to which nutrition has been integrated into crosssectoral policy outputs over time. We observed an overall shift towards increased policy integration for nutrition in Uganda: nutrition goals and instruments gradually increased in number and diversified, and ministries developed relatively extensive networks of actors with whom they collaborate, especially international agencies and partner countries. This process was very gradual, with an acceleration in the period 2011-2015, after the adoption of the UNAP. Importantly, the emergence of substantive and procedural instrument mixes shows that Uganda's integrated nutrition strategies, especially the UNAP, seem to have moved beyond symbolic policy, meaning that strategies were not adopted merely to satisfy donors but were accompanied by substantial measures to support their implementation (cf. Dupuis and Biesbroek 2013). These findings align with various earlier studies, which have found similar increases in sector engagement in nutrition policy (e.g. Turcan and Bene 2017; Pomeroy-Stevens et al. 2016; Hodge et al. 2015).

That said, considerable differences exist across the policy integration dimensions and time periods, and among ministries. Consequently, nutrition integration did not develop along a linear pattern, and for some ministries we also found phases of disintegration. Moreover, we found that the government's financial and regulatory commitments remained largely elusive; this raises questions about the durability and outcomes of interventions. Consistent with this finding, earlier literature stresses that, although SSA governments are increasingly aware of malnutrition, they are often preoccupied with bureaucratic sector arrangements and do not allocate nutrition finances effectively in their resource allocation patterns (cf. Fox et al. 2015; Benson 2008). Inadequate attribution of malnutrition causes (Mogues and Billings 2015) and low budgetary outlays allocated to sectors (Fox et al. 2015) are mentioned as impeding the use of financial instruments.

Our study shows the merits of using the policy integration framework to assess nutrition integration more systematically. Although our insights are country specific, this approach has the potential of comparing efforts across (SSA) governments as well as over time and thus provides more rigour compared to previous approaches. This type of research is important, as the presence of integrated nutrition strategies has been shown not to be a guarantee of actual policy changes (cf. Cejudo and Michel 2017; Nordbeck and Steurer 2016). For the specific
Ugandan context, this approach provides an opportunity to strengthen the systematic monitoring of different ministries and thus hold the government accountable with respect to its commitments to improving nutrition.

\subsection{Future avenues of research}

Our findings give rise to various follow-up questions. An obvious follow-up question is, what explains our findings? The nutrition literature proposes a plethora of malnutrition-related, institutional, and socio-political factors that may impel or impede nutrition policy integration (e.g. Gillespie and van den Bold 2017; Balarajan and Reich 2016; Nisbett et al. 2014b; Rukundo et al. 2014; Drimie and Ruysenaar 2010). However, the precise causal pathways or mechanisms through which these factors affect nutrition integration patterns remain underexplored. A more contextualised exploration of nutrition policy processes to unpack the causal mechanisms explaining why variations exist across ministries and over time is imperative for identifying strategies and opportunities to inform future continuity of such efforts (cf. Biesbroek and Candel 2019; Sieber et al. 2018).

Second, more work is needed on assessing how instruments within and across ministries interact with one another, i.e. whether ultimate instrument mixes are consistent with the nutrition agenda. Additionally, it is important to gain a better understanding of how the different types of instruments that are commonly distinguished in Public Policy literature, i.e. information-, authority-, treasure-, and organisation-based instruments (Hood 1983), can be combined to create synergies (cf. Daugbjerg and Sønderskov 2012). Such research would allow for making the step from analyses of policy outputs to how these affect outcomes on the ground.

Third, although the governance of nutrition involves different levels, our analysis was restricted to policy efforts at national level. Given Uganda's decentralised system however, our observations of shifts towards horizontal policy integration at national level do not necessarily guarantee similar developments at local level (cf. Casado-Asensio and Steurer 2016). Therefore, exploring the interactions across governance levels as well as how integrated nutrition services are ultimately delivered on the ground would be important avenues of further research (cf. Harris et al. 2017).

\subsection{Governance implications}

To ensure that the trend of nutrition integration is not reversed, scaling up the tracking of nutrition policy across countries would be an important step for domestic and international stakeholders to take (cf. Harris et al. 2017). Second, our analysis shows that various aspects of nutrition remain under addressed in Uganda. For example, our analysis shows that overweight and diet-related non-communicable diseases were largely non-existent in policy outputs (cf. Ngaruiya et al. 
2017; Schwartz et al. 2014). In addition, the commitment of various ministries seemed to decrease in the most recent years of the analysis. For example, nutrition goals seemingly reduced in MOH, OPM, and MoES.

Third, the continuity of nutrition integration will benefit from governments normalising it as part of sectors' regular mandates. Our analysis shows that nutrition is currently mostly integrated in the form of ad hoc programmes. Such programmes may have put nutrition on ministry policy agendas but are vulnerable to changes in administrative and political leadership. This approach to integration may be a reflection of weak ownership, variation in priorities, or inadequate capacity within sectors to incorporate such issues into their regular programmes (cf. Leiderer 2015). This is not to say that ad hoc programmes cannot be effective, but we want to caution that this type of integration may not be conducive to the long-term continuity of nutrition policy integration processes.

Fourth, the Ugandan government should consider expanding the types of instruments deployed for improving nutrition. It currently uses primarily information- and organisation-based instruments. Although these have their advantages, a more balanced instrument mix that also includes substantial financial and regulatory tools may prove more effective (Daugbjerg and Sønderskov 2012).

Ultimately, improved nutrition governance in Uganda will rely on whether the government and international agencies manage to harness the current awareness of malnutrition across sectors. This would require scaled-up investments in a diverse mix of instruments as well as the development of an integrated monitoring system to evaluate how interactions between interventions play out on the ground.

Acknowledgements The approval to conduct this study was obtained from the Uganda National Council of Science and Technology through permit number SS83EB and the Mild May Uganda Research Ethics Committee under \# REC REF 0160-2017. The authors acknowledge funding for this research from NUFFIC, the Dutch Organisation for Internationalisation of Education. We express our gratitude to Robert $\mathrm{K}$. $\mathrm{N}$. Mwadime for the stimulating discussions and comments on earlier versions of this manuscript. An earlier version of this paper was presented at the general conference of the European Consortium for Political Research (ECPR) in Hamburg, 22-25 August 2018. We acknowledge the valuable feedback provided by Stefan Ewert of the University of Greifswald; the respondents that attended P501 Trends in Organizational Cross-Overs of Food, Energy, Health and Agriculture and the anonymous reviewer.

\section{Compliance with ethical standards}

Conflict of interest The authors declare that they have no conflict of interest.

Open Access This article is licensed under a Creative Commons Attribution 4.0 International License, which permits use, sharing, adaptation, distribution and reproduction in any medium or format, as long as you give appropriate credit to the original author(s) and the source, provide a link to the Creative Commons licence, and indicate if changes were made. The images or other third party material in this article are included in the article's Creative Commons licence, unless indicated otherwise in a credit line to the material. If material is not included in the article's Creative Commons licence and your intended use is not permitted by statutory regulation or exceeds the permitted use, you will need to obtain permission directly from the copyright holder. To view a copy of this licence, visit http://creativecommons.org/licenses/by/4.0/.

\section{References}

Acosta, A. M., \& Fanzo, J. (2012). Fighting maternal and child malnutrition: Analysing the political and institutional determinants of delivering a national multisectoral response in six countries. Brighton: Institute of Development Studies.

Bachou, H., \& Labadarios, D. (2002). The nutrition situation in Uganda. Nutrition, 18(4), 356-358. https://doi.org/10.1016/s0899-9007(01) 00722-5.

Balarajan, Y., \& Reich, M. R. (2016). Political economy challenges in nutrition. Globalization and Health, 12(1), 70. https://doi.org/10. 1186/s12992-016-0204-6.

Benson, T. (2008). Improving nutrition as a development priority: Addressing undernutrition within national policy processes in subSaharan Africa. Research report 156: International food policy research institute.

Biesbroek, R., \& Candel, J. J. L. (2019). Mechanisms for policy (dis)integration: Explaining food policy and climate change adaptation policy in the Netherlands. Policy Sciences. https://doi.org/10.1007/ s11077-019-09354-2.

Black, R. E., Victora, C. G., Walker, S. P., Bhutta, Z. A., Christian, P., de Onis, M., et al. (2013). Maternal and child undernutrition and overweight in low-income and middle-income countries. The Lancet, 382(9890), 427451. https://doi.org/10.1016/S0140-6736(13)60937-X.

Candel, J. J. L. (2018). Diagnosing integrated food security strategies. NJAS - Wageningen Journal of Life Sciences, 84, 103-113. https:// doi.org/10.1016/j.njas.2017.07.001.

Candel, J. J. L., \& Biesbroek, R. (2016). Towards a processual understanding of policy integration. Policy Sciences, 49(3), 211-231. https://doi.org/10.1007/s11077-016-9248-y.

Candel, J. J. L., \& Biesbroek, R. (2018). Policy integration in the EU governance of global food security. Food Security, 10(1), 195-209. https://doi.org/10.1007/s12571-017-0752-5.

Candel, J. J. L., \& Pereira, L. (2017). Towards integrated food policy: Main challenges and steps ahead. Environmental Science \& Policy, 73, 89-92. https://doi.org/10.1016/j.envsci.2017.04.010.

Casado-Asensio, J., \& Steurer, R. (2016). Mitigating climate change in a federal country committed to the Kyoto protocol: How Swiss federalism further complicated an already complex challenge. Policy Sciences, 49(3), 257-279. https://doi.org/10.1007/s11077-016-9247-z.

Cejudo, G. M., \& Michel, C. L. (2017). Addressing fragmented government action: Coordination, coherence, and integration. Policy Sciences, 50(4), 745-767. https://doi.org/10.1007/s11077-017-9281-5.

Daugbjerg, C., \& Sønderskov, K. M. (2012). Environmental policy performance revisited: Designing effective policies for green markets. Political Studies, 60, 399-418. https://doi.org/10.1111/j.1467-9248. 2011.00910.x.

Drimie, S., \& Ruysenaar, S. (2010). The integrated food security strategy of South Africa: An institutional analysis. Agrekon, 49(3), 316-337. https://doi.org/10.1080/03031853.2010.503377.

Dupuis, J., \& Biesbroek, R. (2013). Comparing apples and oranges: The dependent variable problem in comparing and evaluating climate change adaptation policies. Global Environmental Change, 23(6), 1476-1487. https://doi.org/10.1016/j.gloenvcha.2013.07.022. 
Fan, S., \& Pandya-Lorch, R. (2012). Reshaping agriculture for nutrition and health: An IFPRI 2020 book. Washington, DC: International Food Policy Research Institute.

FAO (2002). World food summit follow-up strategy update for national agricultural development horizon 2010 Uganda. Uganda: FAO.

FAO, \& WHO (2014). Second International Conference on Nutrition: Report of the Joint FAO/WHO Secretariat on the Conference. In ICN2, Rome.

Fox, A. M., Balarajan, Y., Cheng, C., \& Reich, M. R. (2015). Measuring political commitment and opportunities to advance food and nutrition security: Piloting a rapid assessment tool. Health Policy and Planning, 30(5), 566-578. https://doi.org/10.1093/heapol/czu035.

Garrett, J., \& Natalicchio, M. (2011). Working multisectorally in nutrition: Principles, practices, and case studies. Washington, D.C.: International Food Policy Research Institute.

Gillespie, S., Menon, P., \& Kennedy, A. L. (2015). Scaling up impact on nutrition: What will it take? Advances in Nutrition, 6(4), 440-451. https://doi.org/10.3945/an.115.008276.

Gillespie, S., \& van den Bold, M. (2017). Stories of change in nutrition: An overview. Global Food Security, 13, 1-11. https://oi.org/10. 1016/j.gfs.2017.02.004.

HANCI (2017). Key data for Uganda http://africa.hancindex.org/files/ 2017/africa/EN/UG.pdf. Accessed 22 November 2019.

Harris, J. (2019). Advocacy coalitions and the transfer of nutrition policy to Zambia. Health Policy and Planning, 34(3), 207-215. https://doi. org/10.1093/heapol/czz024.

Harris, J., Drimie, S., Roopnaraine, T., \& Covica, N. (2017). From coherence towards commitment: Changes and challenges in Zambia's nutrition policy environment. Global Food Security, doi: https:// doi.org/10.1016/j.gfs.2017.02.006.

Hodge, J., Herforth, A., Gillespie, S., Beyero, M., Wagah, M., \& Semakula, R. (2015). Is there an enabling environment for nutrition-sensitive agriculture in East Africa? Stakeholder perspectives from Ethiopia, Kenya, and Uganda. Food and Nutrition Bulletin, 36(4), 503-519. https://doi.org/10.1177/0379572115611289.

Hood, C. (1983). The tools of government. London.: Chatham House Publishers.

Howlett, M. (2000). Managing the "hollow state": Procedural policy instruments and modern governance. Canadian Public Administration, 43(4), 412-431.

Howlett, M., \& Ramesh, M. (2003). Studying public policy: Policy cycles and policy subsystems (2nd ed.). Toronto: Oxford University Press.

IFPRI. (2016). Global nutrition report 2016: From promise to impact: Ending malnutrition by 2030. Washington, DC: International Food Policy Research Institute.

Jones, B. D., \& Baumgartner, F. R. (2004). Representation and agenda setting. Policy Studies Journal, 32(1), 1-24. https://doi.org/10.1111/ j.0190-292X.2004.00050.x.

Jordan, A., \& Lenschow, A. (2010). Environmental policy integration: A state of the art review. Environmental Policy and Governance, 20(3), 147-158. https://doi.org/10.1002/eet.539.

Kampman, H., Zongrone, A., Rawat, R., \& Becquey, E. (2017). How Senegal created an enabling environment for nutrition: A story of change. Global Food Security. https://doi.org/10.1016/j.gfs.2017.02. 005 .

Knill, C., \& Tosun, J. (2012). Public policy: A new introduction. Basingstoke: Palgrave Macmillan.

Lachat, C., Nago, E., Ka, A., Vermeylen, H., Fanzo, J., Mahy, L., Wüstefeld, M., \& Kolsteren, P. (2015). Landscape nnalysis of nutrition-sensitive agriculture policy development in Senegal. Food and Nutrition Bulletin, 36(2), 154-166. https://doi.org/10. $1177 / 0379572115587273$.

Lafferty, W., \& Hovden, E. (2003). Environmental policy integration: Towards an analytical framework. Environmental Politics, 12(3), 1-22. https://doi.org/10.1080/09644010412331308254.
Leiderer, S. (2015). Donor coordination for effective government policies? Journal of International Development, 27, 1422-1445.

Mogues, T., \& Billings, L. (2015). The making of public investments: Champions, coordination, and characteristics of nutrition interventions (p. 32). Washington, DC: International Food Policy Research Institute.

Ngaruiya, C., Hayward, A., Post, L., \& Mowafi, H. (2017). Obesity as a form of malnutrition: Over-nutrition on the Uganda "malnutrition" agenda. The Pan African Medical Journal, 28, 49. https://doi.org/ 10.11604/pamj.2017.28.49.11176.

Nisbett, N., Gillespie, S., Haddad, L., \& Harris, J. (2014a). Why worry about the politics of childhood undernutrition? World Development, 64, 420-433. https://doi.org/10.1016/j.worlddev.2014.06.018.

Nisbett, N., Wach, E., Haddad, L., \& Arifeen, S. E. (2014b). What are the factors enabling and constraining effective leaders in nutrition? A four country study. IDS Working Paper, 2014(447).

Nordbeck, R., \& Steurer, R. (2016). Multi-sectoral strategies as dead ends of policy integration: Lessons to be learned from sustainable development. Environment and Planning. C, Government \& Policy, 34(4), 737-755. https://doi.org/10.1177/0263774x15614696.

Pelletier, D., Gervais, S., Hafeez-ur-Rehman, H., Sanou, D., \& Tumwine, J. (2017). Boundary-spanning actors in complex adaptive governance systems: The case of multisectoral nutrition. The International Journal of Health Planning and Management, 33(1), e293-e319. https://doi.org/10.1002/hpm.2468.

Persson, Å. (2006). Environmental Policy Integration: An Introduction (PINTS - Policy integration for sustainability). Stockholm: Stockholm Environment Institute.

Pomeroy-Stevens, A., D'Agostino, A., Adero, N., Merchant, H. F., Muzoora, A., Mupere, E., Agaba, E., \& du, L. (2016). Prioritizing and funding the Uganda nutrition action plan. Food and Nutrition Bulletin, 37(4 suppl), S124-S141. https://doi.org/10.1177/0379572116674554.

Reinhardt, K., \& Fanzo, J. (2014). Addressing chronic malnutrition through multi-sectoral, sustainable approaches: A review of the causes and consequences. Frontiers in Nutrition, 1, 13. https://doi. org/10.3389/fnut.2014.00013.

Ruel, M. T., \& Alderman, H. (2013). Nutrition-sensitive interventions and programmes: How can they help to accelerate progress in improving maternal and child nutrition? The Lancet, 382(9891), 536551. https://doi.org/10.1016/S0140-6736(13)60843-0.

Rukundo, P. M., Iversen, P. O., Oshaug, A., Omuajuanfo, L. R., Rukooko, B., Kikafunda, J., et al. (2014). Food as a human right during disasters in Uganda. Food Policy, 49, 312-322. https://doi. org/10.1016/j.foodpol.2014.09.009.

Sabatier, P. A. (1998). The advocacy coalition framework: Revisions and relevance for Europe. Journal of European Public Policy, 5(1), 98 130. https://doi.org/10.1080/13501768880000051.

Schwartz, J., Guwatudde, D., Nugent, R., \& Kiiza, C. (2014). Looking at non-communicable diseases in Uganda through a local lens: An analysis using locally derived data. Globalization and Health, 19(10), 77. https://doi.org/10.1186/s12992-014-0077-5.

Sieber, I. M., Biesbroek, R., \& de Block, D. (2018). Mechanism-based explanations of impasses in the governance of ecosystem-based adaptation. Regional Environmental Change, 18, 2379-2390. https:// doi.org/10.1007/s10113-018-1347-1.

SUN (2010). Scaling up nutrition: A framework for action September 2010. https://scalingupnutrition.org/wp-content/uploads/2013/05/ SUN_Framework.pdf Accessed 30 October 2017.

Tosun, J., \& Lang, A. (2017). Policy integration: Mapping the different concepts. Policy Studies, 38(6), 553-570. https://doi.org/10.1080/ 01442872.2017.1339239.

Turcan, L., \& Bene, T. (2017). A review of policies for improving human nutrition in Uganda and the use of evidence for making policy. Montpellier, France: Agropolis international: Global support Facility for the National Information Platforms for nutrition initiative. 
UBOS (2012). Uganda demographic and health survey 2011. (pp. 139165). Kampala: Kampala, Uganda: UBOS; Calverton, Maryland: ICF international Inc.

UBOS, \& ICF (2018). Uganda demographic and health survey 2016. Kampala, Uganda and Rockville, Maryland, USA: UBOS and ICF.

Webb, P., Stordalen, G. A., Singh, S., Wijesinha-Bettoni, R., Shetty, P., \& Lartey, A. (2018). Hunger and malnutrition in the 21 st century. BMJ, 361. https://doi.org/10.1136/bmj.k2238.

WHO. (2013). Global nutrition policy review: What does it take to scale up nutrition action? (pp. 124). Geneva: World Health Organisation.

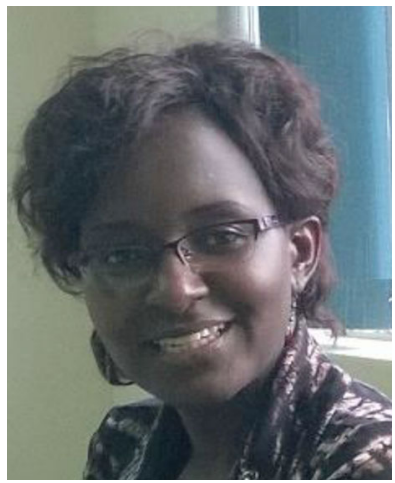

Brenda Shenute Namugumya is a doctoral researcher with Wageningen University \& Research. Her research interests include multisectoral food and nutrition systems, policy and governance approaches, capacity development, and multistakeholder processes. Currently, she uses public policy and governance theories to understand integrated nutrition policies in Uganda. Brenda Shenute has over four years' experience in providing technical assistance to health, agriculture, social development, and planning sectors as well as local governments in Uganda to develop, implement and monitor their nutrition policies. Her MSc in Applied Human Nutrition was obtained from Makerere University. She is a 2016 Alumni of the Mandela Washington Fellowship for Young African Leaders Initiative

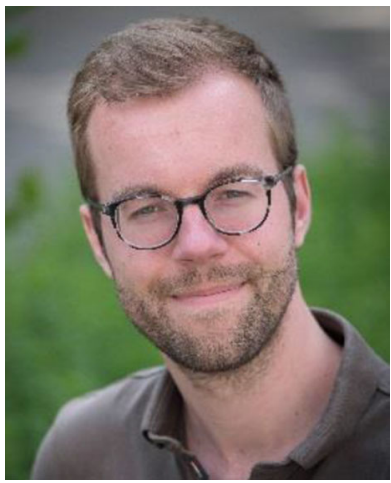

Jeroen Candel is Assistant Professor at the Public Administration and Policy group, Wageningen University \& Research, the Netherlands. His research interests include food and agricultural policy, policy integration, wicked problems, and EU politics. He authored various papers on food security governance, which have been published in both public policy and food (policy) journals. His most recent research focuses on governments' attempts to move towards better integrated food policy

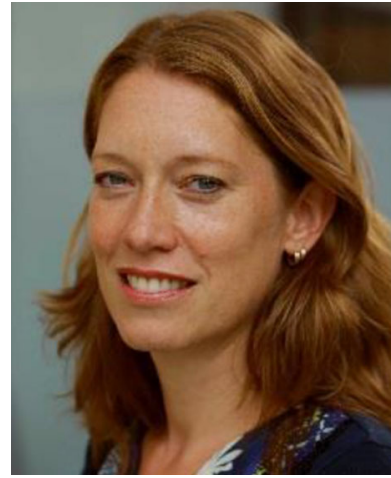

Elise F. Talsma $(\mathrm{PhD})$ is an assistant Professor at the Division of Human Nutrition and Health, Wageningen university and Research. Her research focuses on food and nutrition security applying a food system lens. Her $\mathrm{BSc}, \mathrm{MSc}$ and $\mathrm{PhD}$ were obtained from Wageningen university and her $\mathrm{PhD}$ research was based on fieldwork in Kenya about the efficacy of yellow cassava on the improvement of vitamin A status in Kenyan primary school children. Before and after her studies she has lived in Asia, Africa and Latin America and worked for NGO's, UNICEF and CIAT-Harvestplus

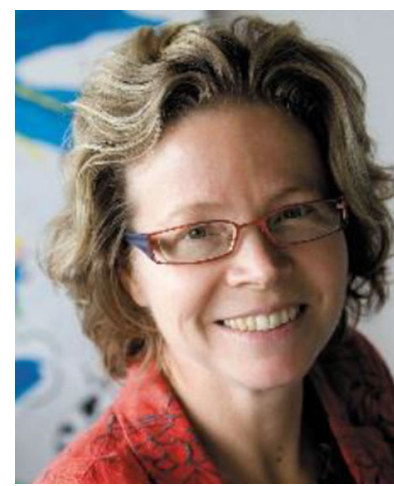

Catrien Termeer is Professor of Public Administration and Policy at Wageningen University, the Netherlands. Her research addresses the governance of wicked problems in the interrelated fields of food, agriculture, climate and energy. Orcid: 0000000173961476 